удК 621.396

\title{
ЭЛЕКТРОДИНАМИЧЕСКИЙ РАСЧЕТ БЕСКОНЕЧНОЙ ПЛОСКОЙ ФАР ПРИ НАЛИЧИИ ДИЭЛЕКТРИЧЕСКИХ СЛОЕВ
}

\author{
МАРЧЕНКО С. В. ${ }^{1}$, МОРОЗОВ В. M. $^{2}$ \\ ${ }^{1}$ Днепродзержинский государственный технический университет, \\ Украина, Днепродзержсинк, 51900, Днепростроевская 2 \\ 2 Днепропетровский национальный университет им. О.Т. Гончара, \\ Украина, Днепропетровск, 49050, ул. Научная, 13
}

\begin{abstract}
Аннотация. Методом пронизывающей области рассмотрено решение трехмерной дифракционной задачи для бесконечной плоской ФАР из прямоугольных волноводов с треугольной сеткой их расположения при наличии плоскослоистого диэлектрического заполнения. Приведены результаты, подтверждающие корректность разработанного электродинамического алгоритма расчета
\end{abstract}

Ключевые слова: ФАР; интегральное уравнение; функция Грина; согласующая структура; метод пронизывающей области

\section{ВВЕДЕНИЕ}

На практике часто используются ФАР с излучателями в виде открытых концов прямоугольных волноводов. По ряду следующих причин такой тип излучающего элемента удобен для ФАР сантиметрового диапазона волн. Он образует естественное продолжение секций волновода, в которых помещены фазовращатели, и позволяет работать на высоком уровне пропускаемой мощности. Его характеристики возможно предварительно рассчитать, что играет важную роль в процессе разработки ФАР. В больших плоских ФАР основная масса элементов центральной области практически однородна по своим характеристикам и особенности поведения достаточно точно описываются поведением излучателей бесконечной АР [1].

\section{ПОСТАНОВКА ЗАДАЧИ}

В данной работе рассматривается задача дифракции электромагнитной волны на плоской волноводной ФАР с диэлектрическими слоями покрытия, которая сканирует в $H$-плоскости. Для решения трехмерной задачи применяется метод пронизывающей области (МПО), в котором учитывается диэлектрическое заполнение. Эта трехмерная задача имеет свои особенности при составлении интегрального уравнения по сравнению с аналогичной задачей без диэлектрического заполнения, а также отличия в пересчете нормальных составляющих векторов напряженностей электрического поля в диэлектрических слоях через аналогичные тангенциальные составляющие внешнего пространства излучения.

На рис. 1 представлена геометрия бесконечной плоской волноводной ФАР с диэлектрическими слоями покрытия. Разобьем всю сложную область определения поля в выбран- 